\title{
Towards an Ontology and Ethics of Virtual Influencers
}

\section{Ben Robinson}

Sydney University

brob9489@uni.sydney.edu.au

\section{Abstract}

In 2018, TIME magazine named Miquela Souza one of the 25 most influential people on the internet, despite the fact she is not a person at all. Miquela is the first digitally created virtual influencer. This paper provides an initial analysis of some of the ontological and ethical issues associated with the rise of virtual influencers on social media platforms like Instagram. Through a focus on Miquela, it is argued that while these fabricated identities may cause uneasiness at first, there is nothing morally significant that distinguishes them from natural, 'real life' influencers. But, far from 'business as usual', the inability to separate 'virtual' and 'real life' influencers raises important questions about the ethical construction of identity, and how this may affect the ongoing preservation of social values like trust in online spaces. The paper draws on literature in personal identity and agency theory to establish the ontological claim that there is no meaningful difference between Miquela and other 'real life' influencers, which leads to the discussion about ethical issues including moral responsibility and motivation, and transparency. As of May 2020, this appears to be the first peer-reviewed article theorising about virtual influencers. There are significant opportunities for further research, both in terms of how we should conceptualise these identities, as well as more empirically based social research into how to preserve social values like trust in online spaces.

Keywords: Ethics; Ontology; AI Ethics; Social media ethics

\section{Introduction}

The rise of virtual identities in online spaces raises a number of important philosophical questions. This discussion paper offers an initial analysis of some of the ontological and ethical issues associated with virtual influencers on Instagram. Through an analysis of Miquela, the first virtual influencer on Instagram, I argue that while these fabricated identities may cause uneasiness at first, there is nothing morally significant that distinguishes them from natural, 'real life' influencers. But, far from 'business as usual', the inability to separate 'virtual' and 'real life' influencers raises important questions about the ethical construction of identity, and how this may affect the ongoing preservation of social values like trust in online spaces.

The paper has three parts. Firstly, I will give an outline of Miquela, the first and most popular virtual influencer, before talking about the rise of these identities more generally, including the technology (or lack of) that underpins them. Secondly, I will discuss some ontological questions including whether their existence online is comparable to existence in real life, and whether this constitutes agency. Thirdly, I will discuss some ethical implications, including the need to assign moral responsibility and understand transparency.

\section{Miquela and the rise of virtual influencers}

There is no strict definition of an influencer, however it can be understood broadly as someone who holds social power and shapes the behaviour of others through their words and actions. These can be online and offline, but the term 'influencer' is particularly used in the context of 
Social Media platforms such as Instagram, Facebook and Snapchat. The Kardashian family have pioneered the influencer economy, with Kym Kardashian and Kylie Jenner reportedly charging brands up to $\$ 1$ million per online post. In 2019, the influencer market was valued at $\$ 8$ billion and this is expected to grow to $\$ 15$ billion by 2022. (Schomer 2019)

Miquela Sousa, better known as Lil Miquela, is the first computer generated social media influencer. ${ }^{1}$ Since Miquela's conception in 2017, she has gained over 2 million Instagram followers and makes a considerable amount of advertising profit for her creators by modelling the clothing of brands including Prada, Samsung and Calvin Klein. She has an identity and life history; she is a progressive 19-year-old musician and arts student who supports Black Lives Matter and transgender rights. She poses with a dull gaze in prominent Los Angeles locations like any other of the thousands of social media influencers on Instagram. Her photo captions are conversational and hip, and she has released a number of pop songs. In 2018, TIME named her as one of the 25 most influential 'people' on the internet. (TIME 2018)

Miquela is created by Brud, a little-known media agency that describes itself as a "group of Los Angeles based problem solvers specializing in robotics, artificial intelligence and their applications to media businesses." (Lewczyk 2020) It is unclear how the images of Miquela are made. Some think that she is completely computer generated; others think she is only partially computer generated, with her image based off of a real life human model whose limbs and head has been digitally distorted before being uploaded online. ${ }^{2}$ It is also unclear where Miquela's personality, life history and the 'content' of her posts come from. While it is possible that it is based off algorithms and machine learning, the likely hypothesis is that the content of her posts, and her narrative and identity are creations of a group of people at Brud. Brud is incredibly secretive about the whole project, but what is clear is that while Miquela does not exist in the flesh-and-bone sense, she has a distinct identity and life history, and carries significant cultural clout evidenced by her millions of followers who are seemingly unperturbed by her 'un-reality'.

So, there are several unanswered questions, including both how the images of Miquela are made, and who determines the content of her posts. The secretiveness of Brud is no doubt a strategy that feeds into the 'myth building' surrounding Miquela - and so far, this seems to have worked. Earlier this year, Brud closed on a deal for \$125 million investment from Spark Capital. (Schieber 2019) And since Miquela's creation, there have been proliferation of other virtual influencers on social media, especially Instagram. ${ }^{3}$ Virtual models are now also being widely used in fashion with marketers using CGI to create the 'perfect' body and face to align with the aesthetic of certain brands.

Part of the appeal of virtual influencers or virtual models is that PR risk can be completely controlled - given all the actions of these influencers are deliberated over from a group of people, the risk of the influencer saying something politically incorrect or misaligned with the brand is close to zero, and there can even be clauses written into contracts that the image of the influencer will remain a certain way and serve a brand's best interest. Miquela is different

\footnotetext{
${ }^{1}$ Link to Miquela's Instagram page (@lilmiquela): https://www.instagram.com/lilmiquela/?hl=en

2 For a conjectural discussion about how the images of Miquela are made, see Eror (2018)

${ }^{3}$ Following the success of Miquela, Brud has created at least two other virtual influencers, with their own unique identity, history and visual aesthetic. See Blawko https://www.instagram.com/blawko22/ and Bermuda https://www.instagram.com/bermudaisbae/
} 
from virtual models because she has an identity and narrative. But, despite the myth building from Brud, there is no evidence that machine learning is involved with the content of her posts. Pundits have claimed that virtual influencers are the future of ads, fashion and commerce, and Juniper Research estimates that the global fashion industry will invest $\$ 3.6$ billion in artificial intelligence technology this year. (Smith 2019)

\section{Ontological issues}

The ontological status of virtual influencers like Miquela is unclear. Physically, it is obvious she does not exist - she is neither a human person nor a robot. The photos of her are partially or fully computer generated and there is no 'real life' Miquela that corresponds to the Instagram fictional identity. But, this identity certainly exists on the online social network and her actions exert considerable influence on the preferences, buying habits, and trends of her followers. When her followers see a new image of Miquela on their phone screen, their relationship with her as an identity is appears almost indistinguishable from other 'real life' social media influencers like Kim Kardashian. Miquela is a living, active identity with a unique visual aesthetic, personality and history that has developed and changed over time. The fact that Miquela's creation and maintenance is a blend of human and computer inputs is seemingly unimportant from the user's perspective - she is very much perceived as real on Instagram, with her fans liking, commenting on, and sharing her posts, like they would to any other 'real life' influencer4. So, on one hand, she clearly does not exist as a physical object in the world, but on the other hand, her identify and self-hood seems to exist on social media just as authentically as other online identities.

This raises questions about personal identity, and what the requirements are for a self to 'exist' in online spaces. In the following section on ethics, I argue that the there are no meaningful differences Miquela's selfhood and the selfhood of other 'real life' Instagram influencers and users. But, here, I want to support this argument by briefly explaining how Miquela's identity appears consistent with the dominant theory in personal identity literature; that of psychological-continuity. The psychological-continuity view of personal identity says that a person's self exists if there is persistence over time between mental states (Olsen 2019). Of course, we cannot say that Miquela exhibits consciousness (or mental states), but there is undoubtedly persistence and psychological continuity in the identity narrative that she displays to her followers on Instagram. From the perspective of the Instagram user, there is no meaningful difference in the psychological continuity displayed by Miquela and that by other 'real life' influencers. Both have seemingly unique values and beliefs expressed as personalities that slowly mould over time but which retain their underlying form.

A second concern is whether virtual influencers can be considered agents. The philosophy of action provides a standard conception of agency, understood in terms of intentionality, where intentionality is explained as causation between mental states and events (Schlosser 2019). So, for a virtual influencer to be considered an agent, it has to be able to act autonomously with a causal connection between its mental states and events. It is quite clear this is not the case for the basic model of virtual influencers like Miquela. She has no mind separate from her creators.

\footnotetext{
${ }^{4}$ By unimportant I don't mean that there are no differences between something that is real and something that is perceived as real, I just mean that from the perspective of an Instagram user, this isn't salient. It appears that people know that she is not real, but act as if she is. Looking through the lens of their phone screen, Instagram users interact with virtual influencers in the same way as real influencers.
} 
Maybe in the future, when influencers start using machine learning and creating content autonomously without direct human input, this might change. Indeed, in April this year, company 1sec unveiled its first virtual influencer, a Japanese-American boy named Liam Nikuro whose creation will apparently involve "innovative content in combination with AI technology." (Tiffany 2019) But, as it currently stands, no details have been released about what this AI technology will involve. As such, I think we should understand these virtual influencers simply as tools used by human agents. That is, despite their human features, they have the same ontological status as say a car or a house - something used by humans to exert their own agency.

The question of ontology and agency is intimately linked with questions about ethics and moral responsibility. I will now talk about some of the ethical issues surrounding virtual influencers.

\section{Ethical issues}

In practice, there is currently no difference between the way that virtual and 'real' identities are treated on platforms like Instagram. Both upload content and interact with their followers. But, perhaps we should be treating these two cases differently, and perhaps Instagram should start monitoring the accounts of its users to separate fact from fiction and to ensure important social values like trust are maintained. If, for instance, it could be demonstrated that the rise of virtual influencers is having a negative effect on trust and cooperation online, this may detract from the legitimacy of platforms and lead to less good moral outcomes. ${ }^{5}$ I will now discuss two reasons why it may be important to draw distinctions between real and virtual influencers: motivation and moral responsibility. I will then argue that perhaps transparency is not as important as first intuited.

It is difficult to ascertain the motivation of virtual influencers like Miquela. It appears that it is simply a way of making money for Brud, her creators, with her identity as an artist and social progressive chosen because it makes her popular. In this way, it just seems like a new form of advertising. While this might seem objectionable, especially because of the social causes Brud is co-opting in order to make her popular, in reality it is no different from what 'real life' influencers do. They promote the best version of themselves, often exaggerating their successes and using Photoshop to make themselves look more attractive. Their business model is surprisingly transparent; the more followers they have, the more they can charge businesses to promote their products. While it may be argued that there is a difference between exaggerating one's identity and completely forging one's identity, it is unclear how this is a meaningful difference. Both are forms of misleading practice with an ulterior motive (making money), so if it is acceptable in the first case (real life influencers), it should be acceptable in

\footnotetext{
${ }^{5}$ And if trust declines online or on certain platforms, there may be negative moral consequences. For instance, Floridi (2010) has spoken about 'ethical infrastructure' that gives rise to situations of 'distributed morality' - aggregate good or bad outcomes are facilitated or hindered by the presences of social values like trust. An example is giving to charity - if trust declines on Instagram, people may be less inclined to donate because they don't know for sure that their money will be safe and delivered to the proper recipient, similarly for online shopping.
} 
the second (virtual influencers). ${ }^{6}$ Motivation does not seem to be a salient factor distinguishing real and virtual influencers.

A second concern relates to moral responsibility and transparency. While real life influencers are clearly responsible for the content of their posts, it is less clear how virtual influencers could be held responsible in the same way. As it currently stands, this is not a big issue. If we assume that Miquela is created by a group of developers at Brud, that group of developers are the one's responsible for Miquela's content: whether it be selling new Prada sunglasses or encouraging young people to go to Black Lives Matter protests. While transparency is definitely an issue, especially with how secretive Brud is, this is a practical rather than theoretical concern. It is simply a matter of finding out who these developers are and who was responsible for certain posts identities like Miquela make. If, however, in the future virtual identities like Miquela start acting autonomously and create content based off algorithms and, say, mining 'trending' topics on Instagram, attributing moral responsibility for their actions would be more difficult. Understanding the moral responsibility of virtual influencers in these cases would rely on the kind of analysis developed in the moral responsibility and Artificial Agent literature. ${ }^{7}$

A further concern is more normative: should we be advocating for more honesty and transparency with how we depict ourselves online, and the standards from others we should expect? I am not going to argue for this here, but I think it is important to note that people hold different intuitions about this. For instance, there is evidence to suggest that people like 'authentic' influencers who show a range of emotions, who show that their life isn't great all the time, who speak about mental health, who posts photos without makeup on etc. This would suggest that values like authenticity are important (for some people). It would be interesting to see if these are the same people who follow virtual influencers. I would hazard a strong bet that they are not. It's likely that different people, and possibly groups of people, generations even, have different intuitions about the authenticity and transparency

\footnotetext{
${ }^{6}$ Again, one might rebut by saying that there is a difference between a small lie and a large lie. The real life influencer from Byron Bay who only uploads gorgeous pictures of themselves in beautiful beach locations and who edits these photos to make their skin look perfect, their teeth whiter and the sunset a deeper colour of orange may not be telling the whole truth, especially when considered that the version of their life displayed is incredibly sanitised and carefully selected, but perhaps this is different from an identity that is totally fictionalised, i.e. virtual influencers. Someone making this point might refer to the moral condemnation that 'cat-fishing' accrues (where people forge their identity on dating apps to get more hits). However, this is disanalogous because unlike a cat-fish on a dating app pretending to be someone else, i.e. lying, some of the virtual influencer online are completely open about the fact they aren't real. For instance, Miquela knows that she is a creation by Silicon Valley entrepreneurs and is open about this to her followers. In such instances, there is a case to be made that virtual influencers are actually the most authentic influencers on the market - they are being completely transparent and open. But, even for cases where virtual influencers are not as open about their creation with their followers, their dishonesty is not disproportionate to what real life influencers do when exaggerating the success and beauty of their lives - both cases operate with the same underlying principle of dishonesty in order to attract followers.

${ }^{7}$ For instance, Thomas Powers (2013) argues that computer systems can be considered moral agents in virtue of their own "causally efficacious intentional states". Holding computers morally responsible (like Miquela if her content was based on AI) does not depend on them having consciousness or intelligence per se.
} 
requirements for online identities, and, by extension, how much they are willing to trust fictional identities online. Given the rise in discussions about trust online, this issue would be well

Some personal anecdotal evidence - when discussing this paper with friends, a common theme is that younger generations are more trusting of technology and online spaces than older generations. What piqued my interest in this topic was because I was incredulous that these virtual influencers had amassed such a massive online following and for reasons not simply out of the shock value or novelty factor - it seemed that younger generations just genuinely don't care that virtual influencers aren't real. Everyone speaks about why transparency is important with emerging tech, but not everyone holds this intuition, particularly younger people. There are deeper debates to be had about the value of transparency and the value of explanation itself. ${ }^{9}$ It is not an apriori truth that we have a right to know who controls the content of posts by virtual influencers like Miquela, and the divergent moral intuitions between generations highlight the need for strong argumentation. ${ }^{10}$ This is an area for further social research - given the rise in discussions about trust online, there may be important policy implications if it were established that different age groups hold different intuitions about particularly recently in the context of discussions about the uptake of the COVID-19 app in Australia if it were established that different age groups held different intuitions Indeed, social research into the potential differences among age-groups

\section{Conclusion}

This discussion is the first step in understanding the ontology and ethics of virtual influencers. It seems likely that the popularity of these identities will only increase in years to come, and so several important questions remain on both a theoretical and empirical level. Theoretical questions include further refinement about the ontological and ethical status of these identities, whether social media platforms have a responsibility to mediate its user's accounts and online personas, and whether individuals have a responsibility to construct their identity online in honest and truthful ways. Empirical questions include further research into the preferences and moral intuitions of people towards fictional identities online and how this affects the trustworthiness of these platforms, or the brands that these identities speak for. The lines between real life and online existence are becoming increasingly blurred as our engagement with platforms and online spaces deepens and becomes more ubiquitous. More theorising needs to be done to ensure social values like trust and transparency are maintained, and to justify the importance of concepts like transparency and explanation.

\footnotetext{
${ }^{8}$ Here, I am treating 'realness' and 'transparency' as broadly analogous concepts.

${ }^{9}$ For a positive account, see Afrashteh, Someh and Davern (2020) who argue that effective explanation facilitates trust and transparency online.

${ }^{10}$ While outside the scope of this paper, arguments can be made that the transparency requirements of emerging technologies are overstated. When we seek professional advice from a doctor or a lawyer, we take this advice without having complete or even partial understanding about the reasoning or knowledge base that has led them to this conclusion. We think that transparency is important, but many of the decisions we make are based off trust, habit and guess work. In any case, if transparency and explanation are continued to be championed as pillars of 'ethical design' in technology, there ought to be strong philosophical justifications for why these values are important.
} 


\section{References}

Afrashteh, Someh \& Davern (2020) 'Explanations as Discourse: Towards Ethical Big Data', Australasian Journal of Information Systems, Vol 24, Selected Papers from the IS Foundations Conference

Eror (2018) "Meet Lil Miquela, the AI Influencer" Highsnobiety, Accessed 10 May 2020 from: https://www.highsnobiety.com/p/lil-miquela-cover-story-issue-16/.

Floridi, L., (2013) 'Distributed Morality in an Information Society', Science and Engineering Ethics,.19(3), pp.727-743

Lewczyk M. (2020) “What are Virtual Influencers, and What Do They Mean for Influencer Marketing?" Sideqik Accessed 10 May 2020 from: https://www.sideqik.com/influencermarketing/virtual-influencers

Olson, Eric T., (2019) "Personal Identity", The Stanford Encyclopedia of Philosophy (Fall 2019 Edition), Edward N. Zalta (ed.), Accessed 10 April 2020 from https://plato.stanford.edu/archives/fall2019/entries/identity-personal/

Powers, T. M., (2013) 'The Moral Agency of Computers', Topoi, Vol.32(2), pp.227-236.

Schlosser, Markus, (2019) "Agency", The Stanford Encyclopedia of Philosophy (Winter 2019 Edition), Edward N. Zalta (ed.), Accessed 10 April 2020 from https://plato.stanford.edu/archives/win2019/entries/agency/

Schomer, A. (2019) 'Influencer Marketing Report', Business Insider, 16 July 2019. Accessed 15 August 2019 from: https://www.businessinsider.com/the-2019-influencer-marketingreport-2019-7/?r=AU\&IR=T

Shieber, J. (2019) 'More Investors are betting on influencers like Lil Miquela' Tech Crunch, 15 January 2019. Accessed 15 August 2019 from: https://techcrunch.com/2019/01/14/moreinvestors-are-betting-on-virtual-influencers-like-lil-miquela/

Smith, S. (2019) 'AI Spending by retailers to reach $\$ 12$ Billion by 2023', Juniper Research. Accessed 15 August 2019 from: https://www.juniperresearch.com/press/pressreleases/ai-spending-by-retailers-reach-12-billion-2023

Tiffany, K. (2019) 'Lil Miquela and the virtual influencer hype, explained', Vox, 3 June 2019. Accessed 15 August 2019 from: https://www.vox.com/thegoods/2019/6/3/18647626/instagram-virtual-influencers-lil-miquela-ai-startups

Time (2018) "The 25 Most Influential People on the Internet" TIME. Accessed 10 May 2020 from: https://time.com/5324130/most-influential-internet/

Turilli, Vaccarro \& Taddeo (2010) 'The Case of Online Trust', Knowledge, Technology \& Policy, 2010, Vol.23(3), pp.333-345.

Copyright: @ 92020 Robinson. This is an open-access article distributed under the terms of the Creative Commons Attribution-NonCommercial 3.0 Australia License, which permits noncommercial use, distribution, and reproduction in any medium, provided the original author and AJIS are credited. 


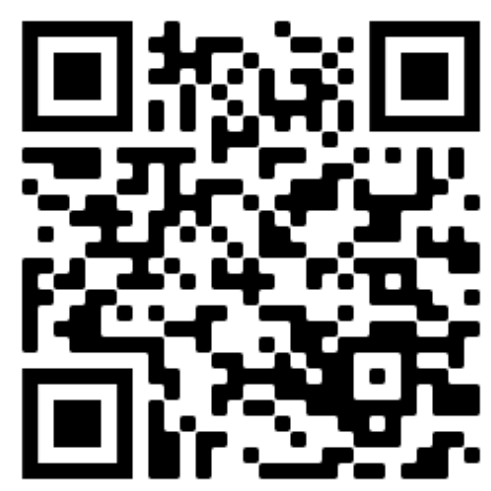

